Objectives: To establish whether a patient information letter could be used to reduce measured biologic drug wastage.

Methods: All SpA patients receiving biologic therapies (infusion or self-injectable) were identified by prescription records. Wastage (recorded by the infusions ward \& home-delivery companies) was reviewed from January 2016 until May 2017. A patient information leaflet (PIL) was developed and sent simultaneously to all patients advising how to minimise wastage (ie: call the infusions ward or delivery companies early when unable to attend and pausing, stopping or switching biologics respectively). The same wastage was measured for 4 months afterwards. Results:

\begin{tabular}{lccc}
\hline Time.frame & $\begin{array}{c}16 . \text { months } \\
\text { Jan.2016 to.May.2017 }\end{array}$ & $\begin{array}{c}4 \text {.months } \\
\text { May.to. } \\
\text { Sep.2017 }\end{array}$ & 12 .month.projection \\
\hline $\begin{array}{lccc}\text { Biologic Drug } \\
\text { wasted }\end{array}$ & $\begin{array}{c}\text { Pre.intervention.wastage } \\
\text { (negative.value) }\end{array}$ & $\begin{array}{c}\text { Post. } \\
\text { intervention. } \\
\text { wastage }\end{array}$ & $\begin{array}{c}\text { Projected.annual. } \\
\text { savings. (positive.value) }\end{array}$ \\
Adalimumab & $-£ 12,598.33$ & $£ 0.00$ & $+£ 9,448.75$ \\
Certolizumab & $£ 0.00$ & $£ 0.00$ & $£ 0.00$ \\
Golimumab & $£ 0.00$ & $£ 0.00$ & $£ 0.00$ \\
Tocilizumab & $-£ 1,612.80$ & $£ 0.00$ & $+£ 1,209.60$ \\
Ustekinumab & $-£ 2,147.00$ & $£ 0.00$ & $+£ 1,610.25$ \\
Secukinumab & $£ 0.00$ & $£ 0.00$ & $£ 0.00$ \\
Infusions(infliximab & $-£ 64,680.00$ & $£ 0.00$ & $+£ 48,510.00$ \\
and biosimilar) & & & \\
Total financial value & $-£ 81,038.13$ & $£ 0.00$ & $+£ 60,778.60$ \\
\hline
\end{tabular}

In the 16 months prior to the PIL intervention an estimated $£ 81,000$ of wastage was measured. Of this, $80 \%$ was due to infusion ward wastage $(n=45$ infliximab infusions) and $20 \%$ was due to self-injectable biologics. Following the PIL intervention, no wastage was measured either on the infusion ward or for self-injectable biologics. This resulted in a projected annual saving of $£ 61,000$ (80\% of which was related to avoidable infliximab wastage). During the observation period the total number of patients taking biologics did not change significantly. No adverse events have been associated with this PIL. Limitations include; a standardised infliximab dose banding was introduced during the final month which may have reduced wastage; Etanercept/etanercept biosimilar data are incomplete as the project is ongoing and are therefore excluded from the analysis.

Conclusions: This is the first intervention demonstrating a reduction in measured biologic drug wastage. It represents a simple, reproducible and sustainable intervention through a collaborative effort between patients and health care providers and offers potential significant savings in a time of austerity.

REFERENCE:

[1] Whiteman, et al. Rheumatology April 2016;55(suppl 1):i119.

Acknowledgements: UCB Pharma UK for sponsoring this project Sheona Gillies - Information Analyst, LTHT facilitating mailshots Disclosure of Interest: None declared

DOI: 10.1136/annrheumdis-2018-eular.3415

\section{OP0301 TWO YEAR COST-EFFECTIVENESS ANALYSIS OF THE CARERA TRIAL IN EARLY RA: A PIGGY BACK STUDY}

S.S. Pazmino ${ }^{1}$, R. Westhovens ${ }^{1,2}$, J. Joly $^{2}$, V. Stouten ${ }^{1}$, D. De Cock ${ }^{1}$, K. Van der Elst $^{1,2}, \mathrm{P}$. Verschueren ${ }^{1,2}$, on behalf of the CareRA study group. ${ }^{1}$ Rheumatology, KU Leuven-Skeletal Biology and Engineering Research Department,

${ }^{2}$ Rheumatology, University Hospitals, Leuven, Belgium

Background: Rheumatoid arthritis (RA) causes high individual, medical and societal costs. EULAR guidelines suggest treating early, intensively and to target using disease modifying anti-rheumatic drugs (DMARDs), preferably with initial glucocorticoid (GC) bridging. COBRA slim, a combination of methotrexate (MTX) with a moderate dose prednisone step down bridge scheme showed a positive efficacy/tolerability balance in the Care in early RA (CareRA) trial. COBRA Slim in comparison to DMARD combination therapy with GC bridging, has the necessary intensity to induce remission, but with a lower risk of severe discomfort or adverse events, decreasing the early need for biologic (b)DMARDs.

Objectives: Perform an economic evaluation on the 2 year pragmatic randomised CareRA trial.

Methods: Patients with early RA ( $\leq 1$ year) naïve to DMARDs were randomised to monotherapy or synthetic (cs)DMARD combination with or without GC bridging, after risk stratification based on classical prognostic markers. Clinical and patientreported data were collected at each visit ( $\geq 10$ times in 2 years).

Direct costs of visits and RA medication (systemic GCs, cs and bDMARDs) over 2 years were calculated for each patient from each of the 5 treatment arms (table 1).
For cost-effectiveness analysis, benefits were expressed as the proportion of patients with DAS28CRP $<2.6$ at year 2 . Missing data was imputed per item with expectation maximisation.

For cost-utility analysis, utilities were calculated using a validated mapping algorithm reconstructing EQ-5D scores based on age, sex, HAQ and pain scores at relevant study visits. Quality-adjusted life years (QALYs) encapsulating the impact of treatment on a patient's length of life and health-related quality of life were calculated as the time-weighted average of all available EQ-5D scores (area under the curve).

Incremental cost-effectiveness ratios (ICERs) from each strategy were calculated. ICERs compare the additional costs a strategy imposes over another with the additional benefits it delivers. Means and medians based methods were calculated with confidence intervals via bootstrapping.

Results: From the initial CareRA cohort $(n=379)$,cost/benefit data of 326 patients was used for a 2 year economic analysis. The mayor driver of direct costs was bDMARDs $(57 \%>87 \%$ of total costs). Number of consultations were comparable $( \pm 11)$ across all treatment strategies.

The cost-effectiveness analysis in the high risk population showed a higher ICER for COBRA Avant Garde (mean $€ 198.65 / 1 \%$, median $€ 78.41 / 1 \%$ ) and a dominated ICER for COBRA Classic (mean $€-181.40 / 1 \%$, median $€-35.01 / 1 \%$ ) compared to the Slim. In the low risk arm, ICERs for COBRA Slim compared to Tight Step Up (TSU) were $€ 46.75 / 1 \%$ (mean) and $€ 43.64 / 1 \%$ (median).

Cost-utility analysis in the high risk arm showed an incremental cost of $€ 1469.36$ for an increased utility of 0.012555 QALYS for COBRA Classic compared to COBRA Slim, resulting in an ICER of $€ 117033.85 /$ QALY.

The ICER of COBRA Avant Garde vs COBRA Slim was $€ 69$ 329.19/QALY. In the low risk arm, the comparison of COBRA Slim to TSU yields an ICER of $€ 1342.78$ per QALY.

\begin{tabular}{|c|c|c|c|c|c|c|c|c|c|}
\hline & \multirow{2}{*}{$\begin{array}{l}\text { Treatment } \\
\text { strategy }\end{array}$} & \multicolumn{2}{|c|}{$\begin{array}{c}\text { Direct costs } \\
\text { Cons siltations + Medication }\end{array}$} & \multicolumn{2}{|c|}{$\begin{array}{l}\text { Effectiveness } \\
\text { DAS28 (CRP) }\end{array}$} & \multicolumn{4}{|c|}{ Utility } \\
\hline & & Mean (BS-CI) & Median (IQR) & Mean & $\%<2.6$ at $Y 2$ & BL & $\mathrm{Y}_{1}$ & $Y_{2}$ & Mean \pm SD \\
\hline \multirow{3}{*}{ 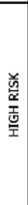 } & $\begin{array}{c}\text { COBRA } \\
\text { Slim } \\
n=87\end{array}$ & $\begin{array}{l}\text { E2 238.62 } \\
\text { (€1 713.15, } \\
\text { E2 896.19) }\end{array}$ & $\begin{array}{c}€ 1145.37 \\
(1034.96-1568.07) \\
\text { BS-CI } \in 1 \quad 102.64, \\
\in 1 \quad 267.93\end{array}$ & \begin{tabular}{|c|}
2.20 \\
\pm \\
0.87
\end{tabular} & $\begin{array}{c}75.9 \% \\
85 .-\mathrm{Cl} \\
67.8 \%, 83.9 \%\end{array}$ & 0.57 & 0.82 & 0.82 & $\begin{array}{c}1.64 \pm 0.31 \\
\text { BS-CI 1.57,1.69 }\end{array}$ \\
\hline & $\begin{array}{l}\text { COBRA } \\
\text { Classic } \\
n=87\end{array}$ & $\begin{array}{l}\epsilon 3707.98 \\
(€ 2643.19 \\
€ 4923.24)\end{array}$ & 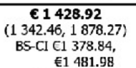 & \begin{tabular}{|c|}
2.30 \\
\pm \\
0.88
\end{tabular} & $\begin{array}{c}67.8 \% \\
85-C I \\
58.6 \%, 75.9 \%\end{array}$ & 0.53 & 0.82 & 0.81 & $\begin{array}{c}1.65 \pm 0.32 \\
\text { BS-CI 1.58,1.72 }\end{array}$ \\
\hline & $\begin{array}{l}\text { COBRA } \\
\text { Avant } \\
\text { Garde } \\
n=77\end{array}$ & $\begin{array}{l}\mathbf{E 3} \mathbf{4 1 0 . 6 3} \\
(€ 2287.82, \\
\epsilon 4833.26)\end{array}$ & $\begin{array}{c}€ 1608.01 \\
(1308.72-1763.05) \\
\text { BS-C1 } \in 1 \text { 1501.61, } \\
C 1626.40\end{array}$ & \begin{tabular}{|c|}
2.03 \\
\pm \\
0.83
\end{tabular} & $\begin{array}{c}\mathbf{8 1 . 8} \% \\
\mathrm{BS} \% \mathrm{CI} \\
74.0 \%, \mathrm{Cg} .6 \%\end{array}$ & 0.56 & 0.82 & 0.86 & $\begin{array}{c}1.65 \pm 0.34 \\
\text { BS-CI 1.58, } 1.72\end{array}$ \\
\hline \multirow{2}{*}{ 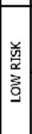 } & $\begin{array}{c}\text { COBRA } \\
\text { Slim } \\
n=34\end{array}$ & $\begin{array}{l}\boldsymbol{\epsilon} 3055.64 \\
(\in 1568.07 \\
\text { C5 383.40) }\end{array}$ & $\begin{array}{c}\boldsymbol{\epsilon 1 1 3 4 . 0 4} \\
(1029.78-1836.78) \\
B S-C 1 \in 1040.69 \\
\epsilon 136.30\end{array}$ & \begin{tabular}{|l|}
1.95 \\
\pm \\
0.86
\end{tabular} & $\begin{array}{c}79.4 \% \\
B 5-c 1 \\
67.6 \%, 88.2 \%\end{array}$ & 0.60 & 0.87 & 0.87 & $\begin{array}{c}1.72 \pm 0.31 \\
\text { BS-CI 1.62,1.83 }\end{array}$ \\
\hline & $\begin{array}{c}\text { Tight Step } \\
\text { up } \\
n=41\end{array}$ & $\begin{array}{c}€ 2877.99 \\
(\in 11263.42, \\
\in 4740.37)\end{array}$ & 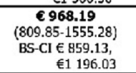 & \begin{tabular}{|c|}
2.23 \\
\pm \\
1.03
\end{tabular} & $\begin{array}{c}75.6 \% \\
\text { BS \%-CI } \\
63.4,85.4 \%\end{array}$ & 0.60 & 0.84 & 0.82 & $\begin{array}{c}1.59 \pm 0.29 \\
\text { BS-CI 1.49,1.68 }\end{array}$ \\
\hline
\end{tabular}

Conclusions: COBRA Slim which consists of an initial combination of MTX and a moderate dosed GC remission induction scheme has a favourable cost-effective and cost-utility profile for patients with early RA independent of their prognostic factors.

Disclosure of Interest: S. Pazmino: None declared, R. Westhovens: None declared, J. Joly: None declared, V. Stouten: None declared, D. De Cock: None declared, K. Van der Elst: None declared, P. Verschueren Grant/research support from: Unrestricted Pfizer Chair in the management of early rheumatoid arthritis DOI: 10.1136/annrheumdis-2018-eular.7296

\section{OP0302 AN EVALUATION OF UTILISATION PATTERNS AND APPROPRIATENESS OF LABORATORY TESTS AMONG NEW REFERRALS TO RHEUMATOLOGISTS: CHOOSING UNWISELY!}

A. Ahrari $^{1}$, S.S. Barrett ${ }^{2}$, S. Rohekar ${ }^{3}$, P. Basharat ${ }^{3}$, G. Rohekar ${ }^{3}$, S. Haig ${ }^{3}$,

J. Pope ${ }^{3} .{ }^{1}$ Internal Medicine; ${ }^{2}$ Medicine, Schulich School of Medicine;

${ }^{3}$ Rheumatology, Western University, London, Canada

Background: Laboratory testing including autoantibodies are common investigations ordered by physicians in diagnosing rheumatic diseases. Tests such as rheumatoid factor (RF) and antinuclear antibody (ANA) have been shown to have low positive predictive value and questionable clinical utility in general practice. ${ }^{1-}$ ${ }^{3}$ Optimizing value in medical care is a worldwide concern. In addition, overuse of diagnostic tests can increase health resource use, lead to unnecessary referrals, and cause anxiety associated with positive results. To that end, the Canadian Rheumatology Association (CRA) joined the national Choosing Wisely Canada Campaign and developed a list of 5 tests with evidence indicating they may not be adding value and in fact be harmful. Among these, ANA testing was identified as one of the tests often inappropriately ordered. ${ }^{3}$ When combined with extractable nuclear antibodies (ENA) and anti-dsDNA, these tests impose a significant cost. 